\title{
Eficácia de nicosulfuron isolado e associado com atrazine no manejo de plantas daninhas em milho ${ }^{1}$
}

\author{
Efficacy of nicosulfuron isolated and associated with atrazine on the weeds \\ management of corn
}

\author{
Paulo César Timossi ${ }^{2}$, Tiago Trevizam de Freitas ${ }^{3}$
}

\begin{abstract}
Resumo - O potencial produtivo da cultura do milho pode ser reduzido quando em convivência com plantas daninhas. Nesta pesquisa, foi avaliado o controle químico de plantas daninhas na cultura do milho BRS 1035, cultivado na segunda safra, com a associação de subdoses do herbicida nicosulfuron com atrazine, com o intuito de reduzir dosagem e aumentar o espectro de ação sobre a comunidade infestante. Os tratamentos herbicidas foram: nicosulfuron a 20, 40 e 60 $\mathrm{g} \mathrm{ha}^{-1}$ e nicosulfuron + atrazine a $20+1000$ e a $40+1000 \mathrm{~g} \mathrm{ha}^{-1}$, além de uma testemunha sem o manejo de plantas daninhas. Os tratos culturais seguiram-se o recomendado para a região. A aplicação dos herbicidas foi realizada com pulverizador de pesquisa pressurizado por $\mathrm{CO}_{2}$ a 210 $\mathrm{kPa}$, com barra de quatro bicos com pontas DG 110.02, a um volume de $200 \mathrm{~L} \mathrm{ha}^{-1}$. As avaliações basearam-se na eficácia de controle da comunidade infestante pelos herbicidas, assim como nas características de produção como massa de 100 grãos e produtividade. Pode-se concluir que a associação de subdoses de nicosulfuron com atrazine foi eficaz no controle de Ipomoea triloba, Alternanthera tenella e Digitaria horizontalis. A aplicação de nicosulfuron + atrazine (40 $+1000 \mathrm{~g} \mathrm{ha}^{-1}$ ) proporcionou a maior produtividade de grãos do híbrido BRS 1035. O acúmulo de massa de 100 grãos não foi afetado pelos tratamentos herbicidas.
\end{abstract}

Palavras-Chave: Alternanthera tenella, Digitaria horizontalis, Ipomoea triloba, Zea mays.

\begin{abstract}
The potential yield of corn may be affected by weed interference. The aim of this research was evaluate the chemical control of weed in fields of corn (BRS 1035), with sub lethal rates of nicosulfuron associated with atrazine in order to reduce doses without lose large spectrum of action in the control of weed community. The herbicides treatments were: nicosulfuron at 20, 40 e $60 \mathrm{~g} \mathrm{ha}^{-1}$, nicosulfuron + atrazine at $20+1000$ and $40+1000 \mathrm{~g} \mathrm{ha}^{-1}$ and a check without weed management. The crops management was the same from region. The spraying was done with $\mathrm{CO}_{2}$ backpack pressurized equipment at $210 \mathrm{kPa}$, with four spray nozzles DG 11002, at $200 \mathrm{~L} \mathrm{ha}^{-1}$ of application volume. The evaluations were based on the efficacy of herbicides and production characteristics and weight of 100 grains. It may be concluded that using nicosulfuron associated to atrazine showed satisfactory control of Ipomoea triloba,

\footnotetext{
${ }^{1}$ Recebido para publicação em 16/08/2011 e aceito em 15/11/2011.

${ }^{2}$ Prof. Adjunto do curso de Agronomia da Universidade Federal de Goiás - Campus Jataí, Rod. BR 364, km192, Jataí, GO. E-mail: ptimossi2004@yahoo.com.br

${ }^{3}$ Engenheiro Agrônomo, graduado pela Universidade Estadual de Goiás - UnU Ipameri. E-mail: tiagotrevizam@bol.com.br
} 
Alternanthera tenella and Digitaria horizontalis. The major grains productivity of corn was obtained with the application of nicosulfuron + atrazine at $40+1000 \mathrm{~g} \mathrm{ha}^{-1}$. The weight of 100 grains was not affected by the weed community and herbicides treatments.

Key-words: : Alternanthera tenella, Digitaria horizontalis, Ipomoea triloba, Zea mays

\section{Introdução}

A cultura do milho, embora seja considerada competitiva, pode ser severamente afetada pela interferência de plantas daninhas, reduzindo a produtividade de grãos. $\mathrm{O}$ estabelecimento da competição entre as plantas daninhas e a cultura do milho pode variar em função da espécie, do grau de infestação, do tipo de solo e das condições climáticas no período. Para Karam \& Silva (2009), as estimativas de redução do potencial produtivo do milho podem variar de acordo com o investimento tecnológico adotado.

Dentre os métodos de manejo de plantas daninhas na cultura, o controle químico tem sido freqüiente devido sua eficácia, conveniência e viabilidade de custos (Jakelaitis et al., 2005a). A aplicação de herbicidas em pós-emergência da cultura e das plantas daninhas surgiu como mais uma ferramenta para o manejo de plantas daninhas (Christoffoleti \& Mendonça, 2001). Entretanto, a eficácia será variável dependendo das condições ambientais, da época de aplicação e da espécie daninha a ser controlada (Zagonel et al., 2000; Merotto Júnior et al., 1997).

Tem-se tornado usual a adoção da associação de atrazine e nicosulfuron, visando ampliar o espectro de controle de plantas daninhas e sua redução na dosagem a ser adotada (Rizzardi et al., 2008; Silva et al., 2005). No sistema Integração LavouraPecuária (ILP) a adoção de subdoses desses herbicidas foi pesquisado por Jakelaitis et al. (2005b), com o objetivo de retardar o desenvolvimento de espécies forrageiras, e controlar plantas daninhas da classe de monocotiledôneas e dicotiledôneas. Desta forma, objetivou-se avaliar a eficácia de dosagens de nicosulfuron, assim como sua associação com atrazine, visando ampliar o espectro de controle de plantas daninhas e sua redução na dosagem a ser recomendada.

\section{Material e métodos}

A pesquisa foi conduzida a campo, na Fazenda Santa Brígida, no município de Ipameri - GO, cujas coordenadas são: latitude $17^{\circ} 39^{\prime} 16,4$ " $\mathrm{S}$, longitude $48^{\circ} 12$ ' 13,3 " $\mathrm{W}$ e altitude de 800 metros. O solo do local foi identificado como LATOSSOLO VERMELHO, com relevo suave, boa drenagem e classe textural argilo-arenosa. Adotou-se o cultivo de milho de segunda safra com o milho híbrido BRS 1035 de ciclo precoce, semeado num espaçamento entrelinhas de $0,85 \mathrm{~m}$, com população de 45.000 plantas por hectare. A semeadura foi realizada em 11 de fevereiro de 2009, com adubação de base com $380 \mathrm{~kg} \mathrm{ha}^{-1}$ do formulado 02-28-16 no sulco e $250 \mathrm{~kg} \mathrm{ha}^{-1} \mathrm{de}$ 36-00-12 em cobertura, aos 15 dias após a semeadura (7dias antes da aplicação dos herbicidas). Devido ao intenso ataque de cigarrinha verde do milho (Empoasca spp.) e lagarta do cartucho (Spodoptera frugiperda), houve a necessidade da aplicação de inseticida na cultura, realizada no estágio V6 e V8. O inseticida adotado foi o Intrepid ${ }^{\circledR}$ a $0,2 \mathrm{Lha}^{-1}$. Quanto a doenças, verificou-se boa sanidade das plantas, sem haver necessidade de controle. Os tratamentos avaliados são apresentados na Tabela 1.

O delineamento experimental adotado foi o de blocos ao acaso, com seis tratamentos 
e quatro repetições. Cada parcela experimental foi composta por cinco linhas da cultura por sete metros de comprimento $(4,2$ × 7,0 m). A área útil de cada parcela foi de duas entrelinhas da cultura por cinco metros de comprimento.

A aplicação dos herbicidas foi realizada em 07/03/2009. A cultura apresentava-se com seis folhas totalmente expandidas (V6), com altura entre 15 e $20 \mathrm{~cm}$. A aplicação foi realizada com pulverizador costal pressurizado com $\mathrm{CO}_{2}$, mantido a pressão constante de 210 $\mathrm{kPa}$, munido de barra de 2 metros com quatro bicos e pontas DG 110 02, com consumo de calda equivalente a $200 \mathrm{~L} \mathrm{ha}^{-1}$. As condições atmosféricas no momento da aplicação $(10 \mathrm{~h}$ $50 \mathrm{~min}$ e $11 \mathrm{~h} 20 \mathrm{~min}$ ) foram: temperatura do ar de $29,1^{\circ} \mathrm{C}$; umidade relativa do ar de $64,5 \%$; ventos intermitentes de até $2 \mathrm{~m} \mathrm{~s}^{-1}$; céu com cobertura de $60 \%$ por nuvens; solo seco à superfície. Já as médias mensais das condições climáticas inerentes ao período de condução do experimento, obtidas no INMET (Instituto Nacional de Metereologia) de Ipameri, GO, são apresentadas na Figura 1.

Tabela1. Herbicidas e suas respectivas dosagens utilizadas no ensaio.

\begin{tabular}{cccc}
\hline Nome Comum & Formulação & $\begin{array}{c}\text { Gramas de } \\
\text { i.a. } \mathrm{ha}^{-1}\end{array}$ & $\begin{array}{c}\text { Dosagem } \\
\left(\mathrm{L} \mathrm{ha}^{-1}\right)\end{array}$ \\
\hline Nicosulfuron & $40 \mathrm{SC}$ & 20 & 0,5 \\
Nicosulfuron & $40 \mathrm{SC}$ & 40 & 1,0 \\
Nicosulfuron & $40 \mathrm{SC}$ & 60 & 1,5 \\
Nicosulfuron + Atrazine & 40 SC + 500 SC & $20+1000$ & $0,5+2,0$ \\
Nicosulfuron + Atrazine $^{1}$ & $40 \mathrm{SC}+500 \mathrm{SC}$ & $40+1000$ & $1,0+2,0$ \\
Testemunha sem manejo & --- & --- & --- \\
\hline
\end{tabular}

${ }^{2}$ Sanson $40 \mathrm{SC} ;{ }^{2}$ Atranex $500 \mathrm{SC}$

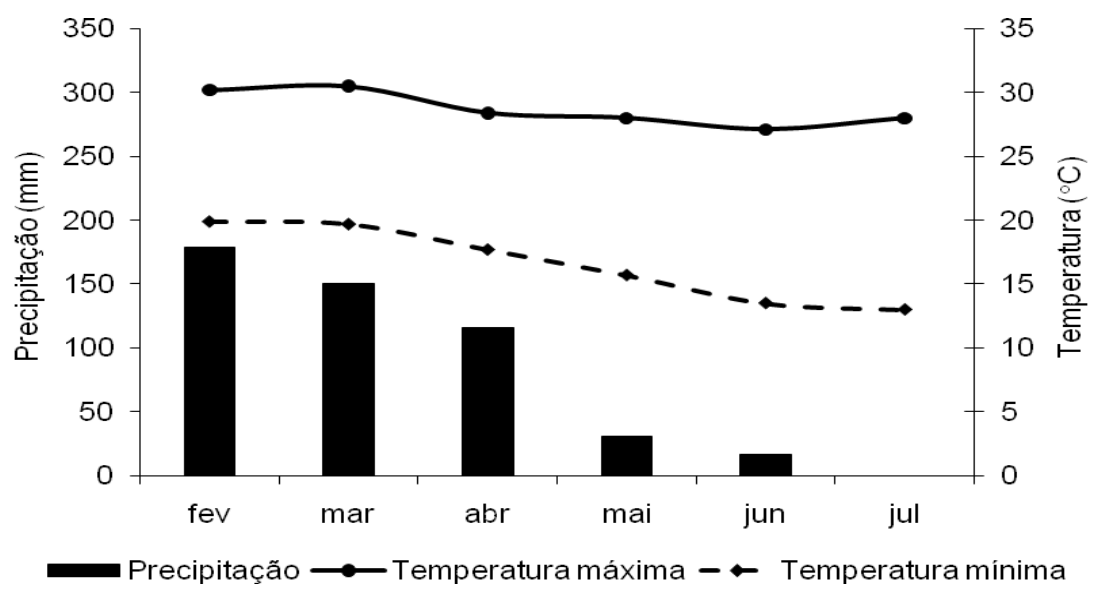

Figura 1. Médias mensais das condições climatológicas inerentes à precipitação pluviométrica, temperatura máxima e temperatura mínima, obtidas durante os meses de fevereiro a julho de 2009 na estação meteorológica do INMET de Ipameri, GO 
Aos 25 dias após a semeadura da cultura, no momento da aplicação dos herbicidas, foi realizada nas parcelas testemunhas, a determinação da densidade e composição específica da flora daninha e seus respectivos estágios de desenvolvimento. Para tal, adotou-se o lançamento por duas vezes, ao acaso, de quadro metálico com $0,5 \times 1,0 \mathrm{~m}$, totalizando $1 \mathrm{~m}^{2}$.

$\mathrm{Na}$ área experimental foram constatadas as seguintes espécies: apaga-fogo (Alternanthera tenella) com 15,2 plantas $\mathrm{m}^{-2}$, corda-de-viola (Ipomoea triloba) com 13,6 plantas $\mathrm{m}^{-2}$ e capim-colchão (Digitaria horizontalis) 11,6 plantas $\mathrm{m}^{-2}$. Também havia em menores proporções e com distribuição casual fedegoso-branco (Senna obtusifolia) e poaia-branca (Richardia brasiliensis), às quais não foram avaliadas. $\mathrm{Na}$ média, a área experimental apresentou densidade de 48 plantas $\mathrm{m}^{-2}$. No momento da aplicação dos herbicidas, as espécies apresentavam-se no estágio de 1 a 6 folhas para as dicotiledôneas e de 1 a 2 perfilhos para a gramínea.

As avaliações basearam-se na caracterização visual de controle de plantas daninhas realizada aos 7, 15, 30 e 45 dias após a aplicação (DAA). Para o controle foi atribuída porcentagem (0 a 100) por espécie daninha e geral, onde zero indica ausência de controle e 100 a morte total das plantas.

Antecedendo a colheita foi feita avaliação sobre a reinfestação pela comunidade infestante remanescente aos tratamentos herbicidas. Para tal, atribuiu-se notas de 0 a $100 \%$ para a cobertura vegetal remanescente. Ainda, na época da colheita, determinou-se a massa seca de 100 grãos, expressa em gramas, em uma amostra por repetição, tomadas ao acaso do volume colhido. Tal amostra foi mantida em estufa a $104,5{ }^{\circ} \mathrm{C}$ por 24 horas e corrigida para $13 \%$ de umidade. Também, determinou-se a produtividade da cultura, expressa em $\mathrm{kg} \mathrm{ha}^{-1}$. Para tal, devido ao ataque de pássaros, preconizou-se colheita manual em três metros lineares, tomados ao acaso na área útil da parcela, extrapolando o peso obtido para hectare. Para obtenção destes resultados, houve adequação dos valores obtidos para a umidade de $13 \%$.

Os dados obtidos nas avaliações foram submetidos à análise de variância pelo teste $\mathrm{F}$ e, para comparação das médias utilizou-se do teste de Tukey a $\mathrm{p} \leq 0,05$. O tratamento sem adoção de herbicidas foi adotado apenas nas análises sobre as características de produção do milho e porcentagem de reinfestação por plantas daninhas.

\section{Resultados e discussão}

O cultivo de milho de segunda safra tem sido adotado em regiões em que as condições climáticas propiciam bom desenvolvimento da cultura. Quase sempre, esta opção tem sido realizada em sequência ao cultivo de soja, no qual já há manejo das plantas daninhas. Em consequência, a densidade da comunidade infestante tende a ser menor. Entretanto, não menos importante, pois quando se trata de espécies de hábito trepador podem interferir no processo de colheita seja mecânica ou manual. De acordo com Karam \& Silva (2009), as espécies presentes na pesquisa são frequentes na comunidade infestante da cultura do milho quando cultivado na região Centro-Oeste.

$\mathrm{Na}$ área experimental, devido ao histórico de cultivo de soja durante anos, constatou-se a presença da espécie Ipomoea triloba, infestação característica da cultura da soja. Esta situação se torna comum em regiões onde é possível realizar dois cultivos sucessivos entre soja e milho em um mesmo ano agrícola.

A porcentagem de controle de Ipomoea triloba pelos herbicidas adotados na pesquisa é apresentada na Tabela 2. Pode-se constatar que 
ao longo das avaliações as maiores taxas de controle para essa espécie foram obtidas com a maior dose de nicosulfuron $\left(60 \mathrm{~g} \mathrm{ha}^{-1}\right) \mathrm{e}$ quando foi associado à atrazine. Entretanto, aos 45 DAA, somente a associação em suas respectivas dosagens proporcionou controle satisfatório.

Para Ipomoea triloba a adoção das subdoses de nicosulfuron quando aplicadas isoladamente não foram eficazes no controle, o que poderia interferir numa possível adoção de sistema ILP em áreas com infestações dessa espécie, interferindo principalmente na colheita da cultura de milho.
Quanto ao controle de Alternanthera tenella, pode-se constatar que a adoção de nicosulfuron a $60 \mathrm{~g} \mathrm{ha}^{-1} \mathrm{e}$ suas respectivas associações com atrazine promoveram os maiores níveis de controle (Tabela 3). Para Spader \& Vidal (2001), a adoção de nicosulfuron, em dose reduzida, e associada com herbicidas mais seletivos às plantas de milho, como atrazine, poderia ser uma alternativa para se obter controle satisfatório das plantas daninhas sem causar danos à cultura.

Tabela 2. Porcentagem de controle de Ipomoea triloba após a aplicação dos herbicidas.

\begin{tabular}{|c|c|c|c|c|c|}
\hline \multirow{2}{*}{ Tratamentos } & \multirow{2}{*}{$\begin{array}{c}\text { Doses } \\
\left(\begin{array}{c}\mathrm{g} \text { i.a. ha } \\
1 \\
\text { ) }\end{array}\right)\end{array}$} & \multicolumn{4}{|c|}{ Épocas de Avaliação } \\
\hline & & $7 \mathrm{DAA}^{1}$ & 15 DAA & $30 \mathrm{DAA}$ & 45 DAA \\
\hline Nicosulfuron & 20 & $52,5 c^{2}$ & $62,5 \mathrm{c}$ & $51,3 \mathrm{c}$ & $45,5 \mathrm{c}$ \\
\hline Nicosulfuron & 40 & $72,5 \mathrm{~b}$ & $76,3 \mathrm{~b}$ & $69,3 \mathrm{~b}$ & $66,7 \mathrm{~b}$ \\
\hline Nicosulfuron & 60 & $73,7 \mathrm{~b}$ & $81,3 \mathrm{~b}$ & $81,3 \mathrm{ab}$ & $77,3 \mathrm{ab}$ \\
\hline Nicosulfuron + Atrazine & $20+1000$ & $97,3 \mathrm{a}$ & $94,0 \mathrm{a}$ & 89,3 a & $86,3 \mathrm{a}$ \\
\hline Nicosulfuron + Atrazine & $40+1000$ & $95,3 \mathrm{a}$ & $96,0 \mathrm{a}$ & $91,3 \mathrm{a}$ & $88,7 \mathrm{a}$ \\
\hline F Trat. & --- & $23,13 * *$ & $26,47 * *$ & $21,78 * *$ & $26,84 * *$ \\
\hline $\mathrm{CV}(\%)$ & --- & 9,8 & 6,5 & 9,3 & 9,3 \\
\hline
\end{tabular}

${ }^{1}$ Dias Após a Aplicação; ${ }^{2}$ Médias seguidas de mesma letra, na mesma coluna, não diferem entre si pelo teste de Tukey.

Tabela 3. Porcentagem de controle de Alternanthera tenella após a aplicação dos herbicidas.

\begin{tabular}{cccccl}
\hline \multirow{2}{*}{ Tratamentos } & \multirow{2}{*}{\begin{tabular}{c} 
Doses \\
\cline { 3 - 6 }
\end{tabular}} & \multicolumn{4}{c}{ Épocas de Avaliação } \\
\cline { 3 - 6 } & $\left.\mathrm{g} \mathrm{i.a.} \mathrm{ha}^{-1}\right)$ & \multicolumn{1}{c}{$7 \mathrm{DAA}^{1}$} & $15 \mathrm{DAA}$ & $30 \mathrm{DAA}$ & $45 \mathrm{DAA}$ \\
\hline Nicosulfuron & 20 & $35,0 \mathrm{~d}^{2}$ & $52,5 \mathrm{c}$ & $43,7 \mathrm{c}$ & $38,0 \mathrm{c}$ \\
Nicosulfuron & 40 & $60,0 \mathrm{c}$ & $71,3 \mathrm{bc}$ & $66,7 \mathrm{~b}$ & $65,5 \mathrm{c}$ \\
Nicosulfuron & 60 & $72,5 \mathrm{bc}$ & $89,5 \mathrm{ab}$ & $85,7 \mathrm{ab}$ & $83,3 \mathrm{ab}$ \\
Nicosulfuron + Atrazine & $20+1000$ & $95,7 \mathrm{a}$ & $94,7 \mathrm{a}$ & $94,3 \mathrm{a}$ & $90,0 \mathrm{a}$ \\
Nicosulfuron + Atrazine & $40+1000$ & $95,0 \mathrm{a}$ & $97,0 \mathrm{a}$ & $94,5 \mathrm{a}$ & $92,0 \mathrm{a}$ \\
\hline F Trat. & --- & $37,55 * *$ & $16,36 * *$ & $23,38 * *$ & $24,89 * *$ \\
CV $(\%)$ & --- & 11,6 & 11,5 & 11,7 & 12,3 \\
\hline
\end{tabular}

${ }^{1}$ Dias Após a Aplicação; ${ }^{2}$ Médias seguidas de mesma letra, na mesma coluna, não diferem entre si pelo teste de Tukey. 
O controle de Digitaria horizontalis (Tabela 4) pelos herbicidas adotados na pesquisa foi satisfatório a partir da adoção de nicosulfuron a $60 \mathrm{~g} \mathrm{ha}^{-1} \mathrm{e}$ em suas respectivas associações com atrazine. Jakelaitis et al. (2005b), obtiveram resultados semelhantes com a adoção dessa associação, embora tenham pesquisado doses inferiores às utilizadas na pesquisa.
Quanto às médias de controle geral (Tabela 5), pode-se constatar a mesma tendência encontrada nas avaliações por espécie. Verifica-se que houve uma diminuição na eficácia dos herbicidas a partir dos 15 dias após a aplicação dos herbicidas. Aos 45 DAA, as médias de controle geral indicam muito boa eficácia do nicosulfuron na dose de $60 \mathrm{~g} \mathrm{ha}^{-1} \mathrm{e}$ de nicosulfuron a 20 e $40 \mathrm{~g}$ associado com atrazine.

Tabela 4. Porcentagem de controle de Digitaria horizontalis após a aplicação dos herbicidas.

\begin{tabular}{|c|c|c|c|c|c|}
\hline \multirow{2}{*}{ Tratamentos } & \multirow{2}{*}{$\begin{array}{c}\text { Doses } \\
\left(\mathrm{g} \text { i.a. } \text { ha }^{-1}\right)\end{array}$} & \multicolumn{4}{|c|}{ Épocas de Avaliação } \\
\hline & & $7 \mathrm{DAA}^{1}$ & $15 \mathrm{DAA}$ & $30 \mathrm{DAA}$ & 45 DAA \\
\hline Nicosulfuron & 20 & $52,5 \mathrm{c}^{2}$ & $52,5 \mathrm{c}$ & $47,0 \mathrm{c}$ & $45,5 \mathrm{c}$ \\
\hline Nicosulfuron & 40 & $78,7 \mathrm{~b}$ & $78,7 \mathrm{~b}$ & $69,3 \mathrm{~b}$ & $65,3 \mathrm{~b}$ \\
\hline Nicosulfuron & 60 & $83,7 \mathrm{ab}$ & $83,7 \mathrm{ab}$ & $85,5 \mathrm{ab}$ & $82,5 \mathrm{ab}$ \\
\hline Nicosulfuron + Atrazine & $20+1000$ & $87,5 \mathrm{ab}$ & $87,5 \mathrm{ab}$ & $83,7 \mathrm{ab}$ & $81,5 \mathrm{ab}$ \\
\hline Nicosulfuron + Atrazine & $40+1000$ & $95,5 \mathrm{a}$ & $95,5 \mathrm{a}$ & $92,7 \mathrm{a}$ & $89,7 \mathrm{a}$ \\
\hline F Trat. & --- & $20,11 * *$ & $20,11 * *$ & $20,59 * *$ & $16,68 * *$ \\
\hline $\mathrm{CV}(\%)$ & --- & 9,1 & 9,1 & 10,6 & 11,9 \\
\hline
\end{tabular}

${ }^{1}$ Dias Após a Aplicação; ${ }^{2}$ Médias seguidas de mesma letra, na mesma coluna, não diferem entre si pelo teste de Tukey.

Tabela 5. Médias de controle geral da comunidade infestante presente na área em diferentes datas após a aplicação dos herbicidas.

\begin{tabular}{cccccc}
\hline \multirow{2}{*}{ Tratamentos } & \multirow{2}{*}{$\begin{array}{c}\text { Doses } \\
\text { (g i.a. ha }\end{array}$} & \multicolumn{4}{c}{ Épocas de Avaliação } \\
\cline { 3 - 6 } & 20 & $45,0 \mathrm{c}^{2}$ & $52,5 \mathrm{~d}$ & $48,7 \mathrm{c}$ & $43,7 \mathrm{c}$ \\
\hline Nicosulfuron & 40 & $61,3 \mathrm{bc}$ & $75,0 \mathrm{c}$ & $65,7 \mathrm{~b}$ & $62,5 \mathrm{~b}$ \\
Nicosulfuron & 60 & $75,0 \mathrm{~b}$ & $86,3 \mathrm{~b}$ & $84,3 \mathrm{a}$ & $82,0 \mathrm{a}$ \\
Nicosulfuron & $20+1000$ & $94,5 \mathrm{a}$ & $90,7 \mathrm{ab}$ & $87,7 \mathrm{a}$ & $85,0 \mathrm{a}$ \\
Nicosulfuron + Atrazine & $40+1000$ & $93,7 \mathrm{a}$ & $95,5 \mathrm{a}$ & $91,5 \mathrm{a}$ & $90,0 \mathrm{a}$ \\
\hline Nicosulfuron + Atrazine & --- & $29,12 * *$ & $77,25 * *$ & $28,30 * *$ & $27,82 * *$ \\
\hline F Trat. & --- & 10,7 & 4,9 & 8,9 & 10,0 \\
CV $(\%)$ & &
\end{tabular}

${ }^{1}$ Dias Após a Aplicação; ${ }^{2}$ Médias seguidas de mesma letra, na mesma coluna, não diferem entre si pelo teste de Tukey.

$\mathrm{Na}$ Figura 2 é apresentada a porcentagem de reinfestação pela comunidade infestante presente na área. Embora tenha sido observada baixa densidade de plantas daninhas, pode-se notar que as espécies predominantes foram bastante agressivas e ao longo do ciclo 
da cultura do milho dominaram a cobertura do solo nas parcelas testemunhas, onde não houve manejo da comunidade infestante. A espécie mais expressiva antes da colheita do milho foi Alternanthera tenella, embora já se encontrasse em estágio de senescência. A espécie Digitaria horizontalis foi praticamente inexistente devido ao término do ciclo de vida das plantas.

Nota-se que as menores taxas de reinfestação podem ser verificadas nos tratamentos herbicidas onde foram adotadas as associações de nicosulfuron + atrazine, confirmando que a associação dos herbicidas é uma alternativa viável. Embora essa associação seja consagrada no setor agrícola, verificou-se pouca disponibilidade de resultados científicos. A maioria dos trabalhos visa principalmente demonstrar a seletividade da associação à cultura do milho (Silva et al., 2005; Jakelaitis et al., 2005a; Rizzardi et al., 2008).

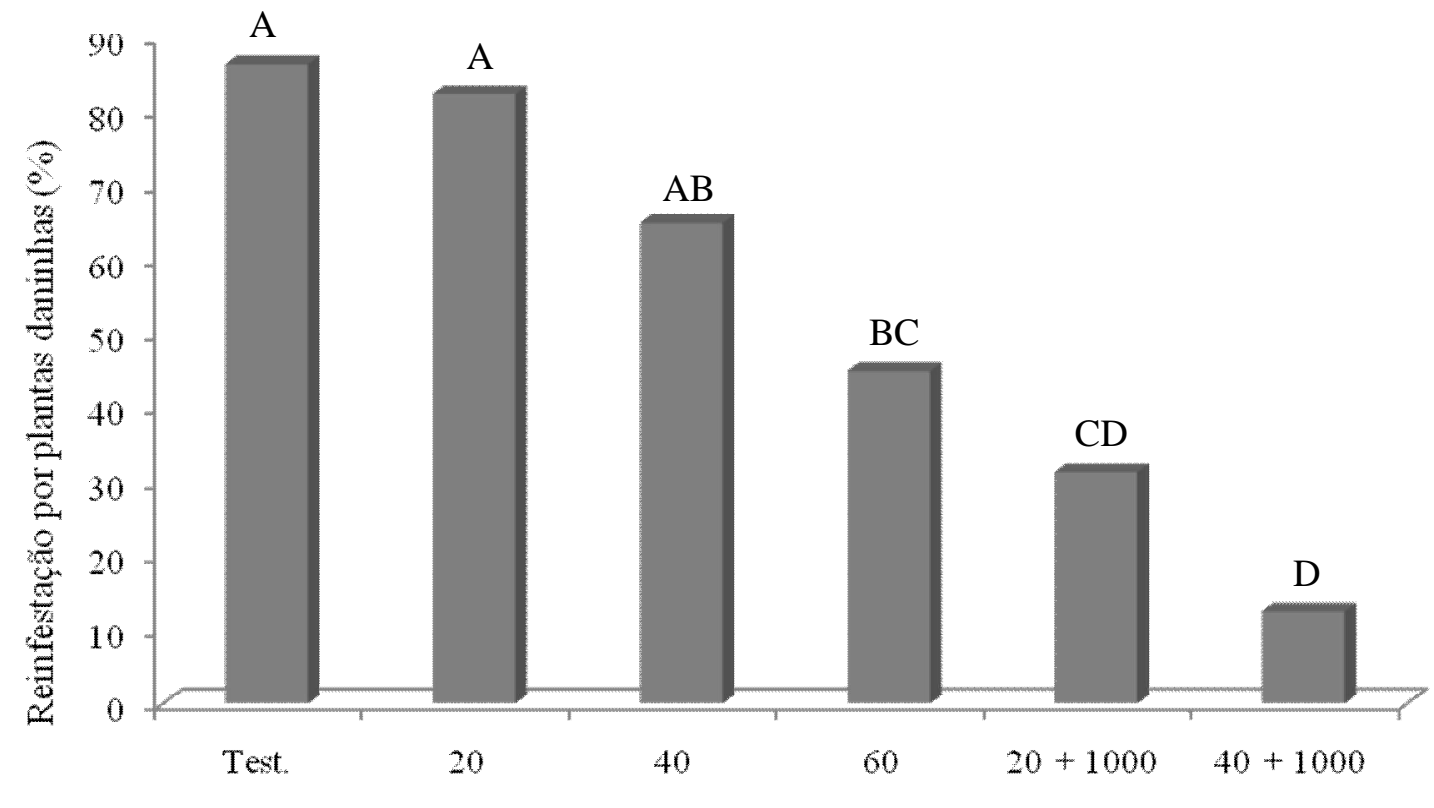

Testemmnha Doses de Herbicidas

Figura 2. Médias da porcentagem da reinfestação por plantas daninhas por época da colheita na testemunha e respectivos tratamentos herbicidas adotados.

Quanto às características agronômicas da cultura do milho (Tabela 6), pode-se constatar que os herbicidas não interferiram no acúmulo de massa de 100 grãos. Entretanto, pode-se constatar o efeito da interferência da comunidade infestante no potencial produtivo da cultura. Confrontando a produtividade alcançada com a adoção de herbicidas ao cultivo da cultura sem manejo, nota-se uma diminuição no potencial produtivo de $24,9 \%$. Rossi et al. (1996), relataram perdas no rendimento de grãos semelhante à obtida na pesquisa. Quando se utilizou a associação de nicosulfuron + atrazine $\left(40+1000 \mathrm{~g} \mathrm{ha}^{-1}\right)$ verificou-se a maior produtividade $(4027,50 \mathrm{~kg}$ $\left.\mathrm{ha}^{-1}\right)$. Estes resultados evidenciam que quando o manejo das plantas daninhas é feito de forma eficiente, a cultura tem a possibilidade de expressar o seu potencial produtivo, alcançando maiores produtividades. 
Tabela 6. Acúmulo de massa seca em 100 grãos e rendimento de grãos em milho.

\begin{tabular}{cccc}
\hline Tratamentos & $\begin{array}{c}\text { Doses } \\
\left(\mathrm{g} \mathrm{i.a.} \mathrm{ha} \mathrm{h}^{-1}\right)\end{array}$ & $\begin{array}{c}\text { Massa de } 100 \\
\text { grãos }(\mathrm{g})\end{array}$ & $\begin{array}{c}\text { Rendimento } \\
\left(\mathrm{kgha}^{-1}\right)\end{array}$ \\
\hline Nicosulfuron & 20 & $26,12 \mathrm{a}$ & $3285,00 \mathrm{ab}$ \\
Nicosulfuron & 40 & $26,90 \mathrm{a}$ & $3431,25 \mathrm{ab}$ \\
Nicosulfuron & 60 & $28,15 \mathrm{a}$ & $3723,75 \mathrm{ab}$ \\
Nicosulfuron + Atrazine & $20+1000$ & $26,40 \mathrm{a}$ & $3521,25 \mathrm{ab}$ \\
Nicosulfuron + Atrazine & $40+1000$ & $26,13 \mathrm{a}$ & $4027,50 \mathrm{a}$ \\
Testemunha sem manejo & --- & $25,52 \mathrm{a}$ & $2700,00 \mathrm{~b}$ \\
\hline F Trat. & ---- & $1,53^{\mathrm{ns}}$ & $2,48^{\mathrm{ns}}$ \\
CV $(\%)$ & --- & 5,5 & 16,1 \\
\hline
\end{tabular}

${ }^{1}$ Médias seguidas de mesma letra, na mesma coluna, não diferem entre si pelo teste de Tukey.

\section{Conclusão}

De acordo com as condições em que foi conduzida a pesquisa pode-se concluir que a adoção de nicosulfuron a $60 \mathrm{~g} \mathrm{ha}^{-1}$ e a associação de subdoses do mesmo com atrazine foram eficazes no controle de Ipomoea triloba, Alternanthera tenella e Digitaria horizontalis.

A aplicação de nicosulfuron + atrazine $\left(40+1000 \mathrm{~g} \mathrm{ha}^{-1}\right)$ proporciona a maior produtividade de grãos do híbrido BRS 1035.

\section{Agradecimentos}

Os autores agradecem o apoio da PROCEMEIAM - Fundação Pró-Cerrado e Meio Ambiente e à Dra. Marize Porto Costa, proprietária da Fazenda Santa Brígida pela concessão da área experimental.

\section{Referências}

CHRISTOFFOLETI, P.J.; MENDONÇA, C.G. Controle de plantas daninhas na cultura do milho: Enfoque atual. In: FANCELLI, A.L.; DOURADO-NETO, D. (Coord.). Milho: tecnologia e produtividade. Piracicaba: ESALQ, 2001. P. 60-95.

JAKELAITIS, A. et al. Efeitos de herbicidas no consórcio de milho com Brachiaria brizantha. Planta Daninha, v.23, n.1, p.69-78, 2005a.

JAKELAITIS, A. et al. Controle de plantas daninhas na cultura do milho-pipoca com herbicidas aplicados em pós-emergência. Planta Daninha, v. 23, n.3, p.509-516, 2005 b.

KARAM, D.; SILVA, J.A.A. Controle químico de plantas daninhas na cultura do milho. In: SEMINÁRIO NACIONAL DE MILHO SAFRINHA, 10. Rio Verde, p.141153, 2009.

MEROTTO JÚNIOR, A. et al. Aumento da população de plantas e uso de herbicidas no controle de plantas daninhas em milho. Planta Daninha, v.15, n.2, p.141-151, 1997.

RIZZARDI, M.A. et al. Controle de plantas daninhas em milho em função de épocas de aplicação de nitrogênio. Planta Daninha, v. 26, n.1, p.113-121, 2008.

ROSSI, I.H. et al. Interferência das plantas daninhas sobre algumas características agronômicas e a produtividade de sete 
cultivares de milho. Planta Daninha, v.14, n.2, aplicado em diferentes estádios de p.134-148, 1996. desenvolvimento da cultura do milho. Ciência SILVA, A.A. et al. Aplicações seqüenciais e épocas de aplicação de herbicidas em mistura com chlorpirifos no milho e em plantas daninhas. Planta Daninha, v.23, n.3, p.523527, 2005.

Rural, v.31, n.6, 2001.

ZAGONEL, J.; VENÂNCIO, W.S.; KUNZ, R.P. Efeitos de métodos e épocas de controle das plantas daninhas na cultura do milho. Planta Daninha, v.18, n.1, p.143-150, 2000.

SPADER, V.; VIDAL, R.A. Seletividade e dose de injúria econômica de nicosulfuron 